\title{
REACH - Opportunities and Risks for a Company Supplying Research Chemicals and Intermediates
}

\author{
Stephan Marfurt*
}

\begin{abstract}
REACH is the proposal of a new legislation to control chemicals in the EU and poses a major challenge to suppliers of chemicals. As a company engaged in supplying more than 80 '000 individual substances to a very diverse customer base, Sigma-Aldrich is particularly affected. The impact of various aspects of REACH, both positive and negative, is discussed. Although the legislation is not yet available in its final version the overall impact is believed to be negative.
\end{abstract}

Keywords: Intermediates · Industry position $\cdot \mathrm{REACH} \cdot$ Research \& Development

\section{Introduction}

The topic discussed here is the current version of REACH as agreed by the Competitiveness Council in December 2005 [1]. The proposal passed by the European Parliament during the first reading differs in some aspects with the new Competitiveness Council's version. The outcome of these discussions seems unpredictable and we can only guess what the final version will entail. Although it can be assumed that the general direction is not going to change, some earlier decisions might again be overturned leading to considerable impact on the implementation and practicality of

\footnotetext{
${ }^{\star}$ Correspondence: Dr. S. Marfurt

REACH. Several studies have investigated the practicality of the planned approach and have shown this to be very low [2][3]. The numerous studies on the impact of REACH [4-6] demonstrate how difficult it is to assess the consequences of this novel approach to chemical control. Whereas aspects such as the costs of testing are quantifiable with high certainty, the practical side of the new legislation, in particular the behaviour of the economic partners, is much more difficult to predict.

Sigma-Aldrich, as the supplier with the largest product portfolio of chemical and biochemical substances for R\&D as well as analytical purposes which currently offers more than 85'000 individual substances plus more than 100'000 substances through its Rare Chemicals Library, is particularly affected by the new regulation. Our products comprise a complete range of substances, from basic chemicals such as solvents, up to highly sophisticated kits for Life Science, which are used in numerous applications in research, development, analytical work and also in production. Although SigmaAldrich as a company would not be considered an SME, the special nature of our business selling rather small quantities of a vast number of products puts us in a special position. Many substances have multiple applications and thus the company's relationship to the customer is different than from a supplier of substances that are tailormade for a specific application. The Table compares the major aspects of the current legislation with the impact of REACH on Sigma-Aldrich.

\section{Registration Requirements}

As with the current legislation, REACH is based on the quantity of manufactured or imported chemicals. New legislation would propose a minimum registration limit of one tonne per year which compares favourably with the limit of $100 \mathrm{~kg}$ per year for new substances applicable since 1992 (Directive 92/32/EC, 7 th amendment of Directive $67 / 548 / \mathrm{EEC}$ [7]). Given the fact that there will now be no distinction between new and existing chemicals it is very important that this limit is increased. This would allow the manufacture or import of numerous chemicals for the purposes of $R \& D$ in small quantities without the need to register. In the Internet consultation which took place in 2003 we had voted for an even higher limit of $10 \mathrm{t} / \mathrm{y}$ but were unsuccessful. Further restrictions might however be applied if the substance is classified as CMR (Carcinogen, Mutagen or a Reproductive hazard).

It seems more than doubtful that an approach is justified which considers as a starting point primarily the hazards and quantity of a substance instead of the actual risks to the general public or the environment. Thus substances which are manufactured or imported in quantities exceeding one tonne per year which do not qualify for the category of intermediates must be registered despite the fact that the substances will be used in R\&D by industrial users (which includes scientific institutions) under carefully controlled conditions. This will affect several hundred substances in Sigma-Aldrich's 
Table. Impact of current EU legislation vs REACH on Sigma-Aldrich

\begin{tabular}{|c|c|c|c|c|c|}
\hline \multicolumn{4}{|c|}{$\begin{array}{c}\text { Current legislation } \\
67 / 548 / E E C\end{array}$} & \multicolumn{2}{|c|}{$\begin{array}{c}\text { Proposed legislation } \\
\text { REACH }\end{array}$} \\
\hline $\begin{array}{c}\text { Existing } \\
\text { chemical } \\
\text { substances } \\
\text { (EINECS) }\end{array}$ & $\begin{array}{c}\text { \# of affected } \\
\text { substances }\end{array}$ & $\begin{array}{c}\text { New } \\
\text { chemical } \\
\text { Sub- } \\
\text { stances } \\
\text { (ELINCS) }\end{array}$ & $\begin{array}{c}\# \text { of } \\
\text { affected } \\
\text { substanc- } \\
\text { es }\end{array}$ & $\begin{array}{l}\text { Phase-In } \\
\text { and new } \\
\text { substances }\end{array}$ & $\begin{array}{l}\text { \# of affected } \\
\text { substances }\end{array}$ \\
\hline
\end{tabular}

Weight band

$R \& D<100 \mathrm{~kg} / \mathrm{y}$

$$
>1000
$$

exempted $>10 ‘ 000$

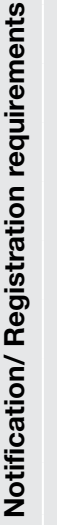

\begin{tabular}{l|l}
$R \& D<1 \mathrm{t} / \mathrm{y}$ & notification \\
$10-100 \mathrm{~kg} / \mathrm{y}$ & not required
\end{tabular}

$>1000$

required

few

$>1000$

required

few

registration

$100 \mathrm{~kg}-1 \mathrm{t} / \mathrm{y}$

$>1000$

required

few

$1-10 \mathrm{t} / \mathrm{y}$

exempted

$100-1000$

required

few

$10-100 \mathrm{t} / \mathrm{y}$

exempted

1-100

required

-

required

100-1000

$>100 \mathrm{t} / \mathrm{y}$

exempted

$>1000$ t/y

exempted

Total

Costs

$>10 ‘ 000$

$>10 ‘ 000$

$<1$ Mio $€$

No

None

No

No

a) Estimates based on the assumption that we are the sole registrant; b) Chemicals Safety Assessment \& Report; c) Classification \& Labelling inventory for hazardous substances placed on the market

portfolio based on today's figures. Depending on the availability of data and the number of members in the respective SIEFs (Substance Information Exchange Fora) our costs for testing and registration could be anywhere between $15-30$ Mio. $€$ over a time period of eleven years. In contrast to the current regulation there will not be any distinction between existing chemicals and new chemicals. EINECS listed substances will therefore qualify as phase-in substances but will have to be registered if exceeding the $1 \mathrm{t} / \mathrm{y}$ limit. The timing of registration is based on substance quantities thus allowing the business to continue to use the lower volume (1-100 t/y) substances for at least eleven years if they were pre-registered. Some companies may make use of this phase-in period or they may try to guarantee the future supply of certain products at an early stage of REACH. If this were the case, downstream users may immediately start to investigate the status of their purchased substances since many will not be in a position to assess whether a specific substance will be registered for their intended use. This would result in a vast number of inquiries being sent back and forth creating a heavy administrative burden for suppliers such as Sigma-Aldrich who have a very broad product portfolio. A decision would then have to be made whether to continue to supply specific substances, to reduce the amount supplied, or to restrict registration to certain uses only. The risk of substances no longer being available on the market will, in the end, also affect R\&D. It is currently very difficult to assess what the impact on our vast portfolio will be since we produce roughly $50 \%$ of our products ourselves and purchase the rest. Our company's position of sourcing could be negatively affected. On the other hand, there might be a chance to produce substances ourselves that are no longer available on the market but are required for R\&D purposes.

The concept of registering 'specific uses and exposure categories', the details of which are still under discussion, has to be seen in the same context. We clearly favour the implementation of a solution involving broad exposure categories along the lines of the VCI proposal [8]. This should include a category of general R\&D use, to make the system manageable. Our customers are performing so many diverse applications with our substances that it would be impossible to register all of these uses. The Business Unit 'SAFC Supply Solutions' is already faced with an increasing number of inquiries regarding the registration of substances for specific applications. As long as no simple criteria exist which address primarily the exposure of a substance to the general public or the environment, it will be very laborious and costly to establish all possible uses for a substance. To overcome this, many studies have indicated that substances used for many purposes today might either be withdrawn from the market, manufactured/imported in lower quantities or for only a limited number of registered uses. A recent workshop highlighted the many unresolved aspects of the concept of exposure scenarios [9].

The bureaucratic efforts will increase for all chemical companies after the implementation of REACH as they will have to monitor the volumes of all their manufactured or imported substances. This entails a distinct change to the current approach of selling existing substances listed on EINECS without any need to register. SigmaAldrich will particularly be affected with such a vast number of marketed substances. We will have to draw special attention to substances of different qualities originating from multiple suppliers.

The exemption from full registration, in the form of so-called 'post card registrations', even for isolated and transported intermediates up to $1000 \mathrm{t} / \mathrm{y}$ is seen as an advantage. Clearly, this will depend on how the authorities will interpret the controlled conditions under which all operations of handling intermediates have to be performed. Since Switzerland currently possesses full exemption from notification for intermediates since 1971 we were in a favourable position with this approach. Sigma-Aldrich is engaged in the fine chemicals business through its SAFC division. The SAFC Pharma unit will certainly profit from this exemption together with the improved exemption for PPORD (Product and Process Oriented Research and Development) substances. The time period for the latter has been extended to 5 plus up to 5 years and 5 plus up to 10 years for substances used in the development of medicinal products. This would be an improvement over today's maximum of two years.

In theory these changes should favour Research \& Development in Europe, one of the main reasons a new legislation was needed, according to the White Paper published in 2001 [10]. The result of a study addressing this issue indicates that companies do not intend to raise their R\&D spending once REACH is implemented [11]. If the production of chemical substances should 
suffer substantially due to these new regulations, it is feared that specific areas of research will leave Europe. This would not hamper global companies like SigmaAldrich, which would simply shift to countries outside of the EU, but would certainly result in a loss of available industry-related positions in Europe.

$\mathrm{REACH}$ targets the production and importation of a substance, thus a substance exclusively produced for export requires registration only if it does not qualify for exemptions. Currently, it depends in which EU country the manufacturing of a substance takes place as to whether or not the production for export requires registration. It is easily possible that production for export could push a substance over a certain registration limit thereby increasing its cost so that production within the EU is no longer feasible. This would represent a potential advantage for companies in Switzerland.

The data generated in order to register the phase-in and new substances would, of course, be of value to our company. However this would only cover a minority of all substances being used for R\&D purposes. Another important aspect of REACH, which might prove itself useful is the anticipated increase of research in reliable QSAR (Quantitative Structure Activity Relationship) programs. As outlined above, the majority of substances used for R\&D are manufactured or imported in such low quantities that they will never undergo testing simply because it would neither be economically feasible nor would it substantially improve the level of protection to our customers since these substances are used only by highly trained professionals under controlled conditions. On the other hand, if it would be possible to better predict the hazardous properties of certain substances the research community would benefit on the whole.

\section{Chemical Safety Assessment and Report}

The new regulations will require chemical companies to produce a Chemical Safety Assessment and Report for substances manufactured/imported in quantities of more than $10 \mathrm{t} / \mathrm{y}$. This will not only add costs but also lead to an increase in the amount information being passed on to our customers through the Safety Data Sheet (SDS). It is unclear of how much information this will be. In the worst case scenario, a customer buying a common solvent would receive a SDS of 20+ pages long, mostly containing information irrelevant for his intended use of the substance. As the SDS have to be provided in the official language of the country where the substance is sold, all this information would have to be translated into each official language. If no predefined sets of phrases are provided, such as the Risk and Safety phrases currently available, this process will prove to be unmanageable.

\section{Classification and Labelling Inventory}

All substances classified as hazardous according to 67/548/EEC would now be covered under the new Classification and Labelling Inventory. According to Articles 109-112 of REACH [12], any manufacturer or importer that places a hazardous substance on the market would need to notify the European Chemical Agency (the Agency) with the hazard classification and the labelling information of this substance. If multiple suppliers should come to a different conclusion regarding the classification and labelling for a substance, for example if using other sources of information, or a different QSAR tool, they must resolve these differences together. We have at least 35000 hazardous substances in our portfolio and this figure will increase once the Globally Harmonised System (GHS) is implemented. GHS introduces new classification criteria for hazardous materials (e.g. mild irritants), which could result in many more substances being considered hazardous. Fahrni and Schmidt [13] mention an example of a substance supplied by ten different companies classified "slightly to distinctly different" by each company. From a scientific point of view one might assume that based on known data, a classification should be quite easy to derive. In reality this assumption is not true. Even after REACH is implemented, many substances will not be completely tested. In most cases, if testing was carried out, the data generated would not result in a different way of handling the substance anyway. The Inventory will be publicly accessible and discrepancies would emerge quickly causing the suppliers of a specific substance to be flooded with questions. This could generate an enormous amount of extra work, ultimately leading to little if any benefit to the customer. The confidentiality of information will also be lost through this inventory. For every hazardous substance placed on the market, even if it is just an intermediate substance, the Agency will have to be notified. This is clearly not what we would call information confidentiality.

\section{Summary}

The purpose of REACH is twofold. On one side, the EU intends to enhance competitiveness and innovation and at the same time achieve a high level of protection for health and the environment. Looking at the current version of REACH it seems doubtful that the legislation will support the goal of innovation. Although the increase of the registration limits of substances for $R \& D$ purposes to $1 \mathrm{t} / \mathrm{y}$ for new substances and the exemptions from full registration for certain categories of intermediates are considered positive, we feel that the legislative package, as a whole, will result in a costly bureaucratic machine, never living up to the intention which motivated the implementation of new legislation. For a company of our size, the participation in hundreds of SIEFs to prepare for the registration of currently EINECS listed substances will constitute a considerable administrative and cost burden. As long as the quantities of manufactured/imported substances are the factors triggering registration, and not the risks associated with a substance being placed on the market, we fear that the chemical industry and the European industry, in general, will suffer heavily from these new bureaucratic regulations. Since no increase in $\mathrm{R} \& \mathrm{D}$ spending is anticipated, the goal of increasing innovation in this area will fail.

\section{Acknowledgement}

Help with the manuscript by Paula Kühnis is gratefully acknowledged.

Received: August 14, 2006

[1] Council of the European Union, 15921/05, 2005 http://register.consilium.europa.eu/ pdf/en/05/st15/st15921-re01.en05.pdf.

[2] REACH Projekt Baden-Württemberg, 2004.

[3] REACH - further work on impact assessment, KPMG study, 2005.

[4] SPORT - Making REACH work in practice, 2005.

[5] Economic Effects of the EU Substance Policy, BDI Research Project, Arther D Little GmbH, 2002.

[6] Extending Impact Assessment, COM(2003) 644 final, 2003.

[7] Official Journal of the European Communities, 5.6.1992, L 154, 1 .

[8] Expositionskategorien - Mensch und Umwelt gezielt schützen, VCI proposal, 2004.

[9] Workshop on REACH exposure scenarios and exposure assessments, Arona, 14.2.2006.

[10] White Paper - Strategy for a future chemical policy, COM 88 final, 2001.

[11] REACH - further work on impact assessment, KPMG study, 2005, p 3.

[12] Council of the European Union, 15921/05, 2005, p 128ff.

[13] M. Fahrni, R Schmid, 'Das Sicherheitsdatenblatt', NDS-U Diplomarbeit FHBB, 2005, p 68. 